\title{
Intranasal teeth in a 3-year-old child with Smith-Lemli-Opitz syndrome
}

\author{
Su-Hyun Shim* \\ Department of Dental Hygiene, Kyungbok University, Pocheon, Republic of Korea
}

Smith-Lemli-Opitz syndrome (SLOS) is a rare autosomal recessive genetic disorder accompanied with congenital anomalies and mental impairment. Clefts of the hard and/or soft palate, small tongue, broad alveolar ridges, and micrognathia have been reported frequently. However, intranasal teeth associated with SLOS have never been described. Here, a case of intranasal teeth in a 3-year-old boy, who was treated operatively for a cleft lip and alveolus at 7 months of age, is reported. Two intranasal teeth were asymptomatic. The teeth were extracted under local anesthesia when they were found to be very loosely attached to the nasal mucosa. Unusual features of this case are highlighted.

Key Words: Cleft palate, Smith-Lemli-Opitz syndrome

(c) This is an open-access article distributed under the terms of the Creative Commons Attribution Non-Commercial License (http://creativecommons.org/licenses/by-nc/4.0) which permits unrestricted noncommercial use, distribution, and reproduction in any medium, provided the original work is properly cited.

\section{INTRODUCTION}

Smith-Lemli-Opitz syndrome (SLOS) is a rare autosomal recessive genetic disorder which is caused by a deficiency of the enzyme 7-dehydrocholesterol reductase which converts 7-dehydrocholesterol to cholesterol. SLOS is estimated to occur in 1 in 20,000 live births, primarily in Caucasians at a rate of 1-2 percent [1]. SLOS is associated with numerous systemic disorders and structural deformities. It characterized by the presence of craniofacial anomalies such as microcephaly, a broad upturned nose, and low set posteriorly rotated ears [2]. Frequent oral manifestations include clefts of the hard and/or soft palate, a small tongue, broad alveolar ridges, and micrognathia [3,4].

Cleft palate has reportedly occurred in 40 to 50 percent of persons with SLOS [4]. Cleft palate can create swallow- ing and sucking difficulties for SLOS patient. In patients with cleft lip and palate, dental anomalies also common in such things as the number of teeth, agenesis, shape, hypoplasia and hypocalcification, eruption, and position and intranasal teeth [5-7].

One of the rare complications of cleft lip and alveolus is nasally erupting tooth [8]. There are few cases reported in literature in which intranasal teeth were present in patients with cleft lip and palate [5,7-12]. The etiology of nasal tooth is not completely understood. However, theories proposed include teeth displaced by trauma [13], osteomyelitis of the maxilla $[14,15]$, obstruction to eruption secondary to crowding of the dentition, persistent deciduous teeth, or exceptionally dense bone and rupturing of a dentigerous cyst into the nasal cavity [16]. Developmental disturbance such as cleft palate has also been proposed $[17,18]$.

Received October 21, 2019; Revised November 25, 2019; Accepted November 26, 2019

*Corresponding author: Su-Hyun Shim, Department of Dental Hygiene, Kyungbok University, 154 Sinpyeong-ro, Sinbuk-myeon, Pocheon 11138 , Republic of Korea.

Tel: +82-31-539-5234, Fax: +82-31-539-5348, E-mail: noblige121@naver.com 
Nasally erupting teeth may be incidentally diagnosed on routine radiographic examination or by presence of symptoms such as difficulty in breathing, pain on sneezing or while blowing the nose $[5,7,8,11]$. Sometimes, however, they are totally symptom-free. Presented here is a case of a 3 year old SLOS patient with operated unilateral cleft lip and palate and unilaterally erupting deciduous right canine and primary first molar in nasal cavity.

The intranasal tooth in children with cleft lip and palate is one of the exceptional conditions encountered in the field of dentistry. Even more, we believe that this case represents the valuable data of the intranasal teeth associated with a cleft lip and alveolus in a patient with SLOS.

\section{CASE}

A 3 year male child operated for unilateral cleft lip at 7 months was referred by a pediatrics consultant to the Dental Department, Seoul Metropolitan Children's Hospital. His

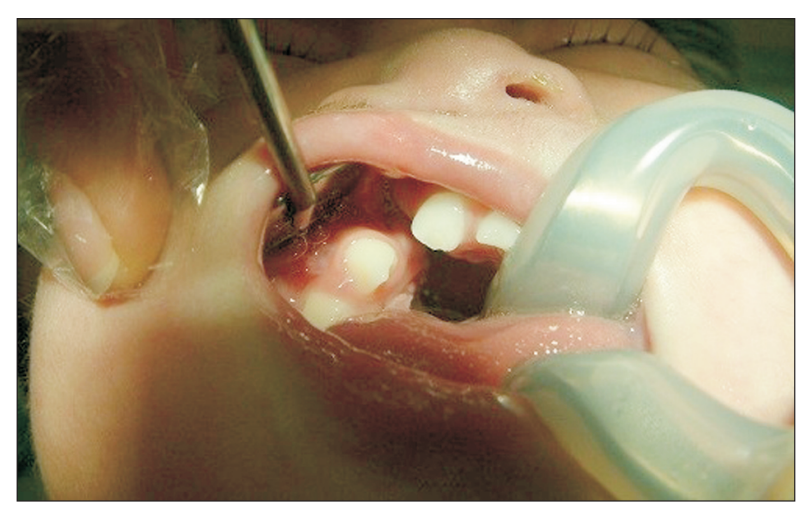

Fig. 1. Smith-Lemli-Opitz syndrome patient with operated cleft lip.

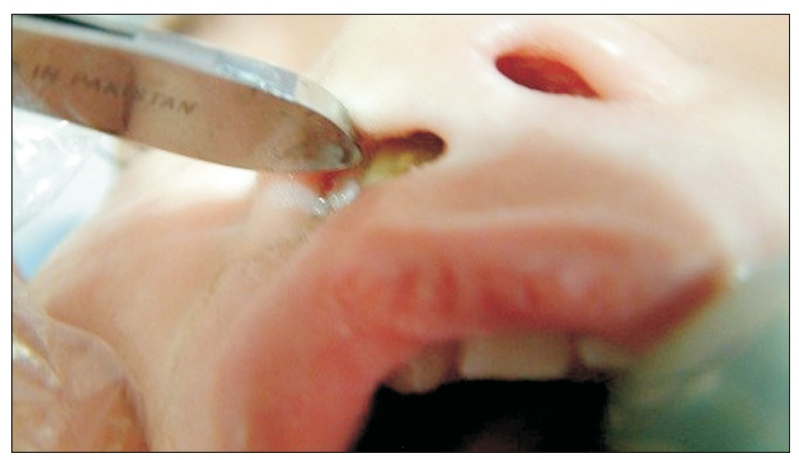

Fig. 2. Intranasal tooth in the right nasal cavity. doctor reported that he had noticed a 'tooth-like' object in the right nostril of the patient. There was no associated history of infection or pain in the nasal cavity. The patient's history revealed that he had been biochemically tested and diagnosed for SLOS. Also he had a cleft lip and alveolus on the right side. He was operated for the treatment of cleft lip at 7 months old (Fig. 1).

On examination, a tooth was clearly seen in the right nasal cavity (Fig. 2). All primary teeth were present with the exception of the right canine and first molar. Considering crown size, location, eruption time and roots' length, we diagnosed they must be the right canine and first molar of the patient's primary dentition. As they were found to be loosely attached to the nasal mucous membrane, they were lifted out with a dental forcep and there was no need of general anesthesia and endoscopic guidance. The nasal mucosa was stripped away from the teeth with a large

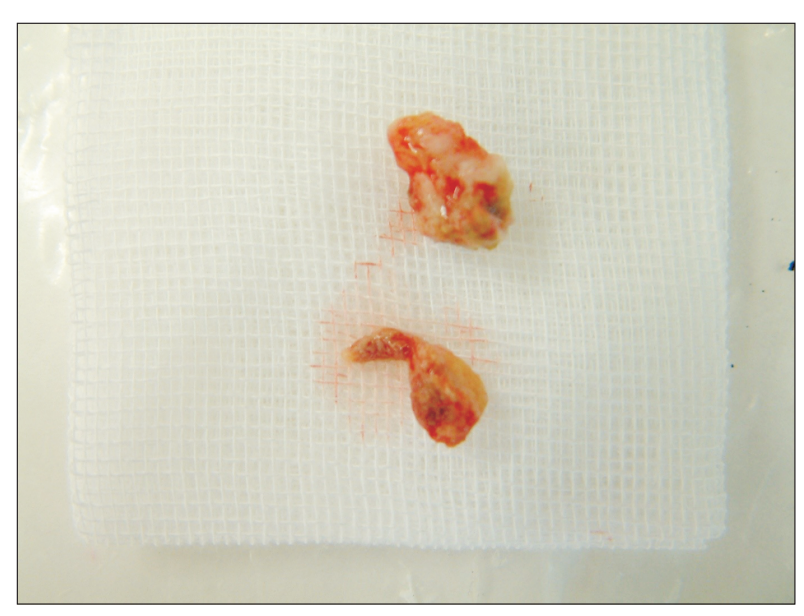

Fig. 3. Extracted intranasal teeth.

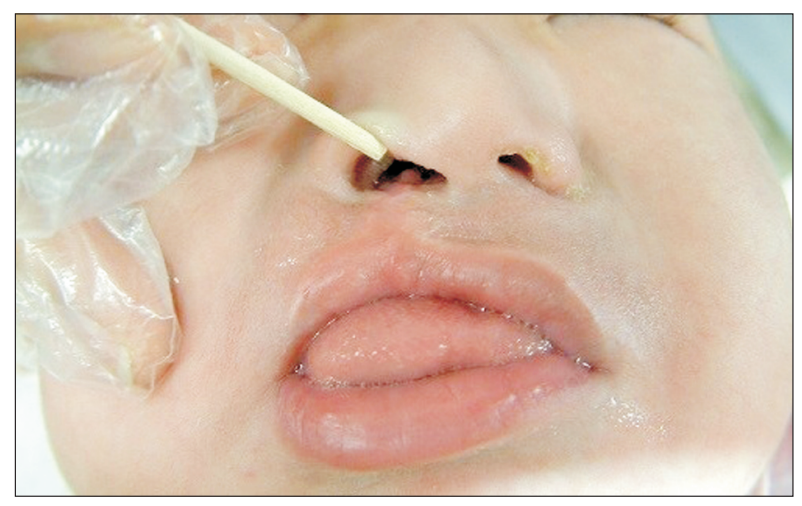

Fig. 4. Five days after the removal of nasally erupted teeth. 
spoon excavator, and then the teeth were extracted with a curved forcep under local anesthesia (Fig. 3). Post-operative nasal bleeding was controlled with Gelform packing. The post-operative recovery was uneventful (Fig. 4) and there has been no recurrence in the two years, post-operatively.

\section{DISCUSSION}

A review of literature revealed the cases of a tooth in nasal cavity. Few cases reported so far. More cases were found in males (60\%) than in female (40\%). And there are 7 cases of intranasal tooth with cleft lip and palate reported in literatures [5,7-12].

Clefts are caused by the failure of fusion between the median nasal process and the maxillary process, or between the palatal processes. These failures are the result of genetic and environmental factors. In South Korea, it occurs in approximately 1 of 554 live birth. Dental abnormalities such as hypodontia, malformation, and abnormal eruption pattern occur frequently in cleft patients. But intranasal tooth are rare, also. The presence of a cleft lip and alveolus of the present case suggested that the incomplete union of embryonic process may have caused the displacement of the tooth germ. The surgical repair of cleft lip at 7 months of age might have further modified the displacement, resulting in the ectopic eruption of the teeth into the nasal cavity [9].

Intranasal teeth present a variety of signs and symptoms such as a feeling of foreign body in the nose [19], nasal obstruction [18,20], nasal discharge [21], recurrent epistaxis [22], nasal congestion [23], chronic intraoral sinus [24], oro-nasal fistula [25], facial pain [26], and foul-smelling serous or purulent rhinorrhea [27]. Occasionally, an intranasal tooth is asymptomatic and may only be recognized incidentally [22].

The diagnosis of intranasal tooth may be made from clinical or radiographic examination. Clinically, an intranasal tooth presents usually as a hard white mass located in the nasal cavity and surrounded by granulation tissue and debris [11]. Radiographically, intranasal tooth may show up on dental panoramic tomograms, occlusal radiographs, or lateral cephalometric views. Radiographic examination, however, may be misleading [9,11]. Differential diagnosis for an intranasal tooth includes foreign bodies, rhinoliths, bony sequestra, neoplasms, and exostoses.

Surgical removal of intranasal teeth under general anesthesia was the preferred treatment. The treatment of these teeth is early surgical extraction to alleviate the symptoms. Those prevent the possible morbidities that include rhinosinusitis, osteomyelitis, nasal septal abscess, oronasal fistula, and nasal deformity [28-30].

We believe that this case represents the report of intranasal teeth in a patient with SLOS. In addition, this case shows intranasal teeth was removed via a nasal approach without general anesthesia and endoscopic guidance.

\section{CONFLICTS OF INTEREST}

The author declares that they have no competing interests.

\section{ORCID}

\author{
Su-Hyun Shim \\ https://orcid.org/0000-0002-8818-6473
}

\section{REFERENCES}

1. Ryan AK, Bartlett K, Clayton P, Eaton S, Mills L, Donnai D, Winter RM, Burn J. Smith-Lemli-Opitz syndrome: a variable clinical and biochemical phenotype. J Med Genet 1998;35:558-565. doi: 10.1136/jmg.35.7.558.

2. Kelley RI, Hennekam RC. The Smith-Lemli-Opitz syndrome. J Med Genet 2000;37:321-335. doi: 10.1136/ jmg.37.5.321.

3. Curry CJ, Carey JC, Holland JS, Chopra D, Fineman R, Golabi M, Sherman S, Pagon RA, Allanson J, Shulman S, Barr M, McGravey V, Dabiri C, Schimke N, Ives E, Hall BD, Opitz JM, Reynolds JF. Smith-Lemli-Opitz syndrome-type II: multiple congenital anomalies with male pseudohermaphroditism and frequent early lethality. Am J Med Genet 1987;26:45-57. doi: 10.1002/aimg.1320260110.

4. Cunniff C, Kratz LE, Moser A, Natowicz MR, Kelley RI. Clinical and biochemical spectrum of patients with RSH/Smith-Lemli-Opitz syndrome and abnormal cholesterol metabolism. Am J Med Genet 1997;63:263-269. doi: 10.1002/(SICI)1096-8628(19970131)68:3〈263::AIDAJMG4>3.0.CO;2-N.

5. Ranalli DN, McWilliams BJ, Garrett WS Jr. Tooth and foreign object in the nasal fossa of a child with a cleft: case 
report. Pediatr Dent 1990;12:183-184.

6. Ranalli DN. Intranasal tooth in a patient with cleft lip and alveolus. Cleft Palate Craniofac J 1996;33:530.

7. Yeung KH, Lee KH. Intranasal tooth in a patient with a cleft lip and alveolus. Cleft Palate Craniofac J 1996;33:157159. doi: 10.1597/1545-1569_1996_033_0157_itiapw_ 2.3.CO_2.

8. Gupta YK, Shah N. Intranasal tooth as a complication of cleft lip and alveolus in a four year old child: case report and literature review. Int J Paediatr Dent 2001;11:221-224. doi: 10.1046/j.1365-263x.2001.00251.x.

9. King NM, Lee AM. An intranasal tooth in a patient with a cleft lip and palate: report of case. J Am Dent Assoc 1987;114:475-478. doi: 10.14219/jada.archive.1987.0124.

10. Lin IH, Hwang CF, Su CY, Kao YF, Peng JP. Intranasal tooth: report of three cases. Chang Gung Med J 2004;27: 385-389.

11. Smith RA, Gordon NC, De Luchi SF. Intranasal Teeth. Report of two cases and review of the literature. Oral Surg Oral Med Oral Pathol 1979;47:120-122. doi: 10.1016/00304220(79)90163-4.

12. Kakade A, Gandhy MM, Damle SG. Management of nasally erupting deciduous canine in operated cleft lip and alveolus patient. J Indian Soc Pedod Prev Dent 2006;24:40-41. doi: 10.4103/0970-4388.22834.

13. Kohli GS, Verma PL. Ectopic supernumerary tooth in the nasal cavity. J Laryngol Otol 1970;84:537-538. doi: 10.1017/ s0022215100072200.

14. Lumba SP, Nirola A, Grewal BS. Healed osteomyeliis of maxilla with tooth in the floor of nose. J Laryngol Otol 1971;85:877-879. doi: 10.1017/s002221510007417x.

15. Dayal PK, Dewan SK, Bihani VK, Dave CJ. Eruption of a tooth into the nasal cavity due to osteomyelitis. J Laryngol Otol 1981;95:509-512. doi: 10.1017/s0022215100091027.

16. Hitschler WJ. Nasal teeth. Arch Otolaryngol 1938;28:911-
925.

17. Endicott CL. A case of a supernumerary incisor eruption into the nose. Br Dent J 1934;56:385-386.

18. Sofat JR, Singh KA. Ectopic super numerary tooth in nasal cavity. J Indian Dent Assoc 1982;54:223.

19. Bertrand L. Dent surnumeraire dans les fosses nasales. J Can Dent Assoc 1964;30:271-272

20. Johnson AP. A case of an intranasal canine tooth. J Laryngol Otol 1981;95:1277-1279. doi: 10.1017/s0022215100092148.

21. Hong CY. Ectopic nasal tooth. Med J Malaysia 1976;30:239240.

22. Sood VP, Kakar PK. Intra-nasal tooth. Eye Ear Nose Throat Mon 1975;54:343-345.

23. Lindsay JR, Karian BK. Ectopic teeth: report of case. J Oral Surg 1969;27:135-136.

24. Martinson FD, Cockshott WP. Ectopic nasal dentition. Clin Radiol 1972;23:451-454. doi: 10.1016/s00099260(72)80015-1.

25. Long CJ. Supernumerary tooth in the nose. Dental Cosmos 1924;66:360.

26. Chopra SS, Joshi MR. Mesiodens erupted in the nasal cavity. Report of a case. Oral Surg Oral Med Oral Pathol 1969;28:856-858. doi: 10.1016/0030-4220(69)90338-7.

27. Hiranandani LH, Melgiri RD. Supernumerary tooth in the floor of the nose. J Laryngol Otol 1968;82:845-848. doi: $10.1017 / \mathrm{s} 0022215100069565$.

28. Alexandrakis G, Hubbell RN, Aitken PA. Nasolacrimal duct obstruction secondary to ectopic teeth. Ophthalmology 2000;107:189-192. doi: 10.1016/s0161-6420(99)00023-8.

29. Lee FP. Endoscopic extraction of an intranasal tooth: a review of 13 Cases. Laryngoscope 2001;111:1027-1031. doi: 10.1097/00005537-200106000-00017.

30. Chen A, Huang JK, Cheng SJ, Sheu CY. Nasal teeth: report of three cases. AJNR Am J Neuroradiol 2002;23:671-673. 